\title{
Radiodensitometric Analysis of Maxillary Sinus-Lift Areas Enforced with Bone Substitute Materials Containing Calcium Phophate
}

\author{
Laura Neimane*, Andrejs Skagers*, Girts Salms*, Liga Berzina-Cimdina** \\ *Riga Stradina University, Institute of Stomatology, Riga, Latvia \\ **Riga Technical University, Rudolfs Cimdins Center for Development and Innovation of Biomaterials, Riga, Latvia
}

\begin{abstract}
Summary
Introduction. An enforcement of atrophic maxilla with biomaterials during sinus-lift surgery improves size and quality of alveolar bone. Radiological densitometric analysis can prove it. Within the study a density of bone was investigated and findings were compared with natural bone around the implants.

Aim of the Study. Was to determine if density around the implant inserted with one stage sinus-lift operation using bone substitute materials increase and if that can be detected radiologically.

Materials and Methods. Totally there were examined 22 patients where 64 implants were inserted in maxilla: 48 implants were inserted with one stage sinus-lift operation using bone substitute materials; represented study group. Sixteen implants were inserted in natural maxillary alveolar bone of the same patients, representing control group.

The density of implant supporting tissue was measured with cone beam computed tomography and expressed in Hounsfield units (HU). The measurements were performed according to standardized pattern.

Results. Densitometric measurements were higher in the study group than in the control group in all points, but statistically significant difference was observed in two measurement sites: buccally in sinus elevation area (BSM) $(p=0.005)$ and palatinally in sinus elevation area (PSM) $(\mathrm{p}=0.0012)$, and corresponding areas in control group.

Conclusions. Surgical elevation of maxillary sinus floor using calcium phosphate bone substitute materials resulted in higher optical density compared to natural bone. Mineralization of the bone, induced by the bone substitute materials, can be detected radiologically
\end{abstract}

Key words: bone substitute materials, calcium phosphate, sinus-lift operation, cone beam computed tomography.

\section{INTRODUCTION}

There is a huge progress in dental implantology, however, the placement of implants in the posterior atrophic maxilla is still considered to be sophisticated due to reduced bone level (9). Bone reduction in this area occurs due to severe bone loss together with maxillary sinus enlargement observed after teeth extraction. Different solutions, such as: the placement of short, even subperiostal, or long implants in pterygoid process, the autogene bone onlay or/and inlay grafting, tilted implants $(2,3,11,14,17,18,22)$ and maxillary sinus floor elevation (sinus-lift operation) using different grafting materials (4) are proposed to bypass the problem. Usually previous bone transplantation is required. An autologous bone graft is considered to be a 'gold standard' because it is immunocompatible. Autogene bone can be acquired from the donor site intraorally or extraorally (5). As bone transplantation, especially if bone is harvested from extraoral site, is an extensive procedure which not all patients are willing or able to experience, different bone substitute materials are widely used in nowadays. Besides, autografts additionally are associated with donor site`s morbidity and unpredictable resorption of bone graft (19). There are studies revealing native bone grafts do not yield optimal outcome because these bone grafts are tended to remodel around the apex of the implant (21). Calcium phosphate containing bone substitute materials present osteoinductive features and these materials can serve as a pier for a bone growth $(1,19)$. There are studies where have been proven that artificial bone substitute materials induces bone formation and resorption. Histological and immunohistochemical analysis showed signs of osteoconduction and osteoinduction (6, 10, 19). Also it was shown that hydroxyapatite (HAp), containing bone substitute materials, does not allow taking place the volume changes, as it is with the autogenous bone chips. HAp provides an adequate resistance against an intra-sinus pressure and re-pneumatisation. HAp also is able to maintain a volume of regenerated bone, by formation of a composite network with the biomaterial particles. Such composite bone presents the highest density (15). It has been proven that bone substitute materials are reliable for bone regeneration in subantral cavities, and vertical defects observed around the implants are comparable to those observed at implants placed in native bone (16).

Different investigation methods, such as: clinical, radiographs, histo-morphologic, endoscopic, analysis of resonant frequency, biomechanical, etc, have 
been applied for evaluation of the results of sinus-lift operation and success of implantations. The radiological method seems to be the least invasive and comfortable for patient. Nevertheless, one should always carry in mind that every radiation exposure to the patient should be justified.

The aim of the study was to determine if density around the implant inserted with one stage sinus-lift operation using bone substitute materials increase and if that can be detected radiologically.

\section{MATERIALS AND METHODS}

Current study was a retrospective radiological study. Totally there were radiologically examined 22 patients. These patients were outpatients that came for implant control during 2010. All patients were in well general health condition. All together there were 64 implants inserted in maxilla. In all patients there were implants inserted in maxillary alveolar bone with both methods: with and without enforcement with calcium phosphate biomaterials. Study group was constructed of 48 implants that were inserted in to the atrophic maxillary alveolar bone with one stage sinus lift operation through lateral window approach with various $1.0-2.0$ $\mathrm{ml}$ calcium phosphate bioceramics granules. Following calcium phosphate biomaterials were used for sinus augmentation operation: Curasan Cerasorb (Germany), Frios Algipore (Germany), Straumann BoneCeramic (Switzerland), RTU Hap granules (LR Patent Nr.P-10-30, Latvia). Control group was constructed of 16 implants that were inserted in to the maxillary alveolar bone of same patients. No biomaterials were used to support and enforce implants in control group. Implants were inserted in usual way as there was enough natural bone to support the implant.

The operation was performed at least seven months before radiological investigation. The longest period between operation and scanning was 7 years. To investigate all sinus lift sites and implants inserted the cone beam computed tomography (CBCT, I-CAT Next Generation, USA) scanning was performed. The cone beam source operated at $120 \mathrm{kV}, 5 \mathrm{~mA}$. The scanning parameters were as follows: diameter $-16 \mathrm{~cm}$, height -13 $\mathrm{cm}$, duration -8.9 seconds. The images of 0.3 voxel size were obtained. Obtained CBCT scans were reformatted and examined using ExamVision software (I-CAT Next Generation, USA). Measurements were done by the sole radiologist. Each implant was aligned into perpendicular position in relation to floor and evaluated in all planes. Measurements were performed in coronal view which passes through the longitudinal axis of the implant.

Density of surrounding tissue around the implant in study group was measured on the following five points (figure 1): density of buccal alveolar bone (BAB), density of buccal bone substitute materials in sinus elevation area (BSM), apically of the implant (AP), density of palatinal bone substitute materials in sinus elevation area (PSM) and density of palatinal alveolar bone $(\mathrm{PAB})$ supporting implant. In control group similar measurements were done in the alveolar bone (figure 1). The measuring field was $0.5 \mathrm{~mm}^{2}$. Measurements were registered in Hounsfield units (HU).
Results were presented as mean and standard deviation (SD). For statistical analysis non-parametric test of significance the Mann-Whitney U test was used for assessment of both groups. Statistical significance was defined as $\mathrm{p}<0.05$.

\section{RESULTS}

There were radiologically examined 48 implants placed into atrophic posterior segments of maxillary bone due to surgical sinus floor elevation using bone substitute materials. An average age of study group was 46.7 years, ranging from 32 to 68 years; and it was 48.8 years in the control group, ranging from 32 to 60 . Twenty five implants $(52 \%)$ were inserted into maxilla of females and 23 implants $(48 \%)$ were inserted into males.

Reconstruction of the images and alignment of the implants using similar patterns was applied to each patient. It was done for standardization of the method and in order to repeat the procedure.

There was the following mean density around the implants on measuring points in the study group (table 1): buccal alveolar bone - $1018.70 \mathrm{HU} \pm 387.32$, buccal bone substitute materials in sinus elevation area 953.60 HU \pm 392.37 , apically to the implant - 766.90 $\mathrm{HU} \pm 444.09$, palatinally substitute materials in sinus elevation area - 776.60 HU \pm 371.61 , palatinal alveolar bone supporting implant - $800.60 \mathrm{HU} \pm 399.02$. The mean density around the implants on measuring points in the control group was as follows (table 1): buccal alveolar bone at the crest $-891.00 \mathrm{HU} \pm 294.00$, buccal bone at the apical portion of the implant - 636.80 HU \pm 221.03, apically to the implant $-570.10 \mathrm{HU} \pm 346.77$, palatinal bone at apical portion of implant - 482.60 HU \pm 215.32, palatinal alveolar bone at the crest $-702.70 \mathrm{HU} \pm$ 259.00 .

There was found statistically significant difference in density measurements between both groups - p value was 0.005 on buccal bone substitute materials (BSM) in sinus elevation area in the study group, and on buccal bone at apical portion of the implant in control group. Statistically significant difference also was found in density measurements on area of substitute materials of palatinal bone in the region of sinus elevation in the study group, and on buccal bone at the apical portion in control group. Here the p value was 0.0012. No statistically significant differences were found on the other three points of the measurements. The $p$ value for density measurement of BAB was 0.257, for apical tissue density it was 0.13 , for palatal alveolar bone 0.28 . There was no statistically significant difference regarding radiodensity found among the cases where different biomaterials were used during sinus-lift procedure.

\section{DISCUSSION}

The cone beam computed tomography represents new options for radiological investigation of maxillofacial region. Feasibility to measure density of tissue is one of the options. However, we should understand that the measurements of density in Hounsfield units in CBCT images symbolize a comparative measurement, not a real value of density due to technical specificity. Control group was represented by the implants inserted 
in to the natural maxillar alveolar bone. No bone substitute calcium phosphate biomaterials were used for enforcement of these implants. As that is the basic implant insertions method then these implants were considered the control group.

All sinus lift operations were performed using biomaterials that contain calcium phosphate. In this study comparison of different materials were not curried out as groups were small and the main emphasis was on calcium phosphate that is main component of all biomaterials used in this study. Recent studies in vitro and in vivo showed that such materials provide excellent biocompatibility. In scaffolds of such materials increased number of osteoblasts can be found (23). It is intelligible that a composite of natural bone and bone substitutes, which includes calcium phosphate - after considerable time span, radiologically represents higher density than natural bone alone. Besides, it has been proven in many studies that bone substitute materials used in sinus floor elevation procedures are osteoconductive and osteoinductive, providing good scaffold for new bone formation $(6,9,10,19,21)$. Measurements around implants in both groups facilitate reproducibility and repeated measurements.

In this study, statistically significant differences of density measurements were found between buccal and palatal sinus-lift sites bone substitute materials areas in the study group, and palatal and buccal bone in the apical portion of the implants in the control group. It represents that mixture of newly formed bone and bone substitute materials around implant construct dense bedding. However, this was not found in apical portion of the implant were also mixture of newly formed bone and bone substitute material was expected. This could be explained that re-pneumatisation of the sinus takes place and this site is more subjected to the remodelling changes, leading to the less material in this area (16). Sinus lift sites when bone substitute materials containing calcium phosphate are used usually remains dimensionally stable for longer period (15). The most dimensional changes occur within first 3 years after operation $(7,8,12,24)$. Several short-time radiological studies demonstrated that majority of resorbtions take place in the first year after sinus lift operation $(7,13)$. In our study most of implants were examined long after this span of the time, what means - when the most dimensional changes are ceased. Another reason could be the surgical technique, if too little material were inserted in to the apical portion of the implant due to sophisticated operation performed.

There were no statistically significant differences detected between other two measurement areas palatal alveolar and buccal alveolar bone at the crest in both groups. However, the mean density was higher in the study group. This points the tendency of calcium phosphate bone substitute materials induce mineralization or provides remineralisation of the natural contact bone. There is the study showing that sinus-lift operation when calcium phosphate containing materials were used in long-term decrease augmented area and increase radiodensity in residual, previous demineralised alveolar bone (20).
This study employed small subject groups. To support our results more investigation is required with larger groups.

Conclusion

Surgical elevation of maxillary sinus floor using calcium phosphate bone substitute materials resulted in higher optical density of the mixture of newly formed bone and substitute material around the dental implant as in natural bone alone. Mineralization of the bone, induced by the bone substitute materials, can be detected radiologically.

Wider investigation with larger subject groups is required.

\section{ACKNOWLEDGEMENTS}

Current study was supported by state research project of Latvia 'New Materials and Technologies for Evaluation and Substitution of Biologic Tissue'.

\section{Conflict of interest: None}

\section{REFERENCES}

1. Abukawa H, Papadaki M, Abulikemu M, Leaf J, Vacanti JP, Kaban LB, Troulis MJ. The engineering of craniofacial tissues in the laboratory: a review of biomaterials for scaffolds and implant coatings // Dent Clin North Am, 2006; 50: 205-216.

2. Anitua E, Orive G, Aguirre JJ, Andia I. Fiveyear clinical evaluation of short dental implants placed in posterior areas: a retrospective study // J Periodontol, 2008; 79: 42-48.

3. Aparicio C, Perales P, Rangert B. Tilted implants as an alternative to maxillary sinus grafting: a clinical, radiologic, and periotest study // Clin Implant Dent Rel Res, 2001; 3: 39-49.

4. Browaeys H, Bouvry P, De Bruyn H. A literature review on biomaterials in sinus augmentation procedures // Clin Implant Dent Related Res, 2007; 9: 166-177.

5. De Vicente JC, Hernandez-Vallejo G, BranaAbascal P, Pena I. Maxillary sinus augmentation with autologous bone harvested from the lateral maxillary wall combined with bovine-derived hydroxyapatite: clinicaland histologicobservations // Clin Oral Impl Res, 2010; 21 : 430-438.

6. El-Ghannam A. Bone reconstruction: from bioceramics to tissue engineering // Expert review of medical devices, 2005; 2: 87-101.

7. Hallman M, Hedin M, Sennerby L, Lundgren S. A prospective 1 - year clinical and radiographical study of implants placed after maxillary sinus floor augmentation with bovine hydroxyapatite and autogenous bone // J Oral Maxillofac Surg, 2002; 3: 277-284.

8. Hatano N, Shimizu Y, Ooya K. A clinical long term radiographic evaluation of graft height changes after maxillary sinus floor augmentation with 2:1 autogenous bone/ xenograft mixture and simultaneous placement of dental implants // Clin Oral Implants Res, 2004; 15: 339-345.

9. Heinemann F, Mundt T, Biffar R, Gedrange $T$, Goetz W. A 3-year clinical and radiographic study 
of implants placed simultaneously with maxillary sinus floor augmentations using new nanocrystaline hydroxyapatite // J Physiol Pharmacol, 2009; 60: 91-97.

10. Henkel KO, Gerber T, Lenz S, Gundlach KK, Bienengraber V. Macroscopical, histological and morphometric studies of porous bone-replacement materials in minipigs 8 months after implantation // Oral Surg Oral Med Oral Pathol Oral Radiol Endod, 2006; 102:606-613.

11. Hirsch JM, Ohrnell LO, Henry PJ, Andersson L, Brånemark PI, Chiapasco $\mathrm{M}$, Gynther G, Finne K, Higuchi KW, Isaksson S, Kahnberg KE, Malevez C, Neukam FW, SevetzE, Urgell JP, Widmark G, Bolind P. A clinical evaluation of the zygoma fixture: one year of follow-up in 16 clinics // J Oral Maxillofac Surg, 2004; 62: 22-29.

12. Kahnberg KE, Wallstrom M, Rasmusson L. Local sinus lift for single - tooth implant. I. Clinical and radiographical follow - up // Clin Implant Dent Relat Res, 2011; Sept: 231-237.

13. Kirmeier R, Payer $M$, Wehrschuetz M, Jakse N, Platzer S, Lorenzoni $M$. Evaluation of three dimentional changes after sinus floor augmentation with different grafting materials // Clin Oral Implants Res, 2008; Apr: 366 - 372.

14. Krekmanov L, Kahn M, Rangert B, Lindstrom $\mathrm{H}$. Tilting of posterior mandibular and maxillary implants for improved prosthesis support // Int J Oral Maxillofac Implants, 2000; 15: 405-414.

15. Lambert F, Leonard A, Drion P, Sourice S, Layrolle $\mathrm{P}$, Rompen E. Influence of space-filling materials in subantral bone augmentation: blood clot vs. autogenous bone ships vs. bovine hydroxyapatite // Clin Oral Impl Res, 2011 ; 22 : 538-545.

16. Maiorana C, Sigurta D, Mirandola A, Garlini G, Santoro F. Bone resorption around dental implants placed in grafted sinuses: clinical and radiological follow-up after up to 4 years // Int J Oral and Maxillofac Implants, 2005; 20: 261-266.

17. Renouard F, Nisand D. Short implants in the severely resorbed maxilla: a 2-year retrospective clinical study// Clin Implant Dent Relat Res, 2005; 7: 104-110.

18. Romeo E, Ghisolfi M, Rozza R, Chipasco M, Lops D. Short $(8 \mathrm{~mm})$ dental implants in the rehabilitation of partial and complete edentulism: a 3- to 14 year longitudinal study // Int J Prosthodont, 2006; 19: 586-592.

19. Salma I., Pilmane M., Skagers A., Vetra J., Salms G., Berzina-Cimdina L., Serzane R. Early morphofunctional response of contact tissue after intraosal implantation in rabbit jaw of pure synthetic hydroxyapatite bioceramic materials and HAp saturated with lidocaine // Stomatologija, 2009; 11: 4: 113-118.

20. Salms G, Skagers A, Zigurs G, Salma I, Cimdina R, Berzina L, Priednieks J. Outcome of SEMADOS dental implants in one stage with sinus floor elevation by HAp granules // Stomatologija, 2002; 4: 2 - 8 .

21. Sbordone L, Toti P, Menchini-Fabris G, Sobrdone
C, Guidetti F. Implant success in sinus - lifted maxillae and native bone: a 3 - year clinical and computerized tomographic follow-up // Int J Oral Maxillofac Implants, 2009; 24: 316-324.

22. ten Bruggenkate CM, Asikainen P, Foizik C, Krekeler G, Sultter F. Short (6-mm) nonsubmergent dental implants : results of a multicenter clinical trial of 1 to 7 years // Int J Oral Maxillofac Implants, 1998; 13: 791-795.

23. Warnke PH, Seitz H, Warnke F, Becker ST, Sivananthan S, Sherry E, Liu Q, Wiltfang J, Douglas T. Ceramic scaffolds produced by computerassisted 3D printing and sintering: characterization and biocompatibility investigation // J Biomed Mater Res B Appl Biomater, 2010; 93: 212-217.

24. Zijderveld SA, Schulten EA, Aartman IH, ten Bruggenkate CM. Long - term changes in graft height after maxillary sinus floor elevation with different grafting materials: radiographic evaluation with a minimum follow - up of 4.5 years // Clin Oral Implants Res, 2009; Jul: 691-700.

\section{Address:}

Dr. Laura Neimane

Dzirciema Street 20, Riga LV-1007, Latvia

Phone: 0037129232455

E-mail: laura.neimane@inbox.lv

Table 1. Findings of densitometric analysis in the control group and in the study group

\begin{tabular}{|c|c|c|c|c|c|}
\hline \multirow{2}{*}{} & \multicolumn{2}{|c|}{ Control group (HU) } & \multicolumn{2}{|c|}{ Study group (HU) } & \multirow{2}{*}{ p value } \\
\cline { 2 - 5 } & Mean value & SD & Mean value & SD & \\
\hline 1. BAB & 891.00 & 294.00 & 1018.7 & 387.32 & 0.257 \\
\hline 2. BSM & 636.80 & 221.03 & 953.60 & 392.37 & $0.005^{*}$ \\
\hline 3. AP & 570.10 & 346.77 & 766.90 & 444.09 & 0.132 \\
\hline 4. PSM & 482.60 & 215.32 & 776.60 & 371.61 & $0.0012^{*}$ \\
\hline
\end{tabular}

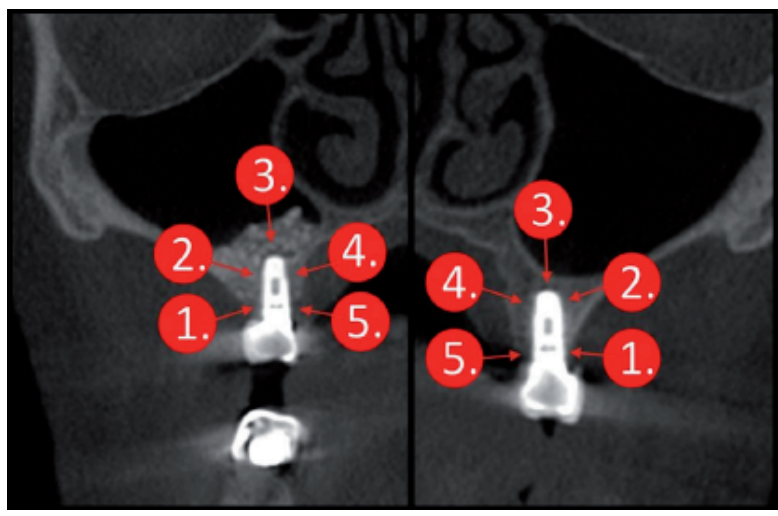

\begin{tabular}{|l|c|c|c|c|c|}
\hline 5. PAB & 702.70 & 259.00 & 800.60 & 388.02 & 0.280 \\
\hline
\end{tabular}

Fig. 1. Measurements of density around the implant placed into atrophic maxilla with bone substitute materials (left), and around the implant placed into atrophic maxilla without sinus elevation procedure (right) 